Louisiana State University

LSU Digital Commons

6-1-2006

\title{
Reproductive behavior of the Yellow-crowned parrot (Amazona ochrocephala) in Western Panama
}

Angélica M. Rodríguez Castillo

Universidad Autónoma de Chiriquí

Jessica R. Eberhard

Smithsonian Tropical Research Institute

Follow this and additional works at: https://digitalcommons.Isu.edu/biosci_pubs

\section{Recommended Citation}

Rodríguez Castillo, A., \& Eberhard, J. (2006). Reproductive behavior of the Yellow-crowned parrot (Amazona ochrocephala) in Western Panama. Wilson Journal of Ornithology, 118 (2), 225-236.

https://doi.org/10.1676/05-003.1

This Article is brought to you for free and open access by the Department of Biological Sciences at LSU Digital Commons. It has been accepted for inclusion in Faculty Publications by an authorized administrator of LSU Digital Commons. For more information, please contact ir@lsu.edu. 


\title{
REPRODUCTIVE BEHAVIOR OF THE YELLOW- CROWNED PARROT (AMAZONA OCHROCEPHALA) IN WESTERN PANAMA
}

\author{
Authors: RODRÍGUEZ CASTILLO, ANGÉLICA M., and EBERHARD, \\ JESSICA R.
}

Source: The Wilson Journal of Ornithology, 118(2) : 225-236

Published By: The Wilson Ornithological Society

URL: https://doi.org/10.1676/05-003.1

\begin{abstract}
BioOne Complete (complete.BioOne.org) is a full-text database of 200 subscribed and open-access titles in the biological, ecological, and environmental sciences published by nonprofit societies, associations, museums, institutions, and presses.
\end{abstract}

Your use of this PDF, the BioOne Complete website, and all posted and associated content indicates your acceptance of BioOne's Terms of Use, available at www.bioone.org/terms-of-use.

Usage of BioOne Complete content is strictly limited to personal, educational, and non - commercial use. Commercial inquiries or rights and permissions requests should be directed to the individual publisher as copyright holder.

\footnotetext{
BioOne sees sustainable scholarly publishing as an inherently collaborative enterprise connecting authors, nonprofit publishers, academic institutions, research libraries, and research funders in the common goal of maximizing access to critical research.
} 


\title{
REPRODUCTIVE BEHAVIOR OF THE YELLOW-CROWNED PARROT (AMAZONA OCHROCEPHALA) IN WESTERN PANAMA
}

\author{
ANGÉLICA M. RODRÍGUEZ CASTILLO ${ }^{1,3}$ AND JESSICA R. EBERHARD ${ }^{2,4,5}$
}

\begin{abstract}
We studied the breeding biology of the Panamanian subspecies of the Yellow-crowned Parrot, Amazona ochrocephala panamensis, during 1997-1999 in the province of Chiriquí, Panama, to provide basic information regarding the breeding behavior and reproductive success of these parrots in their natural habitat. We recorded parrot behaviors throughout the reproductive period, monitored nest success, and characterized occupied and non-occupied tree cavities. All breeding attempts involved a male-female pair. Clutch size ranged from 2 to 4 eggs, which were incubated only by the female, beginning when the first egg was laid. Incubation averaged 25 days and the eggs hatched asynchronously. During the incubation period, females remained inside the nest for long periods of time, though they often departed from the nest area during early mornings and late afternoons, presumably to forage; during this period, males were not observed entering the nest, though they often remained nearby. During the nestling period, males contributed significantly to feeding the offspring. Pairs nested in trees that were in good or fair condition, and did not favor cavities in any one tree species. As found in many other field studies of parrots, breeding success was low. Only 10\% (1997-1998) and 14\% (1998-1999) of the nests survived poaching and natural predation. Because nest poaching was the primary cause of breeding failure and poses a serious threat to population viability, we also present data on poaching techniques and the local trade of nestling parrots. Overall, the pool of breeding adults is likely made up of aging individuals that are not being replaced, setting the stage for a rapid population decline. Received 13 January 2005, accepted 23 November 2005.
\end{abstract}

The genus Amazona consists of 31 species distributed throughout the Neotropics (Juniper and Parr 1998); however, the breeding biology of only a few species has been studied (see below). Nest poaching and the capture of adult birds for the pet trade, together with habitat loss due to deforestation, have contributed to the precipitous decline of Amazona populations in Central America, South America, and the Caribbean region (Forshaw 1989, Juniper and Parr 1998, Wright et al. 2001). Like many of the eight other subspecies that form the Yellow-crowned Parrot complex (Juniper and Parr 1998, Eberhard and Bermingham 2004), Amazona ochrocephala panamensis has not escaped these pressures (Asociación Nacional para la Conservación de la Naturaleza 1995, Autoridad Nacional del Ambiente 1995a). In Panama, the population of this subspecies has declined considerably due to nest

\footnotetext{
${ }^{1}$ Escuela de Biología, Univ. Autónoma de Chiriquí, David, Panamá.

${ }^{2}$ Smithsonian Tropical Research Inst., Apdo. 2072, Balboa, Panamá.

${ }^{3}$ Current address: Estafeta Universitaria, UNACHI, David, Panamá.

${ }^{4}$ Current address: Biological Sciences Dept. and Museum of Natural Science, 202 Life Sciences, Louisiana State Univ., Baton Rouge, LA 70803, USA.

${ }^{5}$ Corresponding author; e-mail: eberhard@1su.edu
}

poaching (Ridgely 1981) and the loss of nesting habitat to agricultural and cattle-grazing activities (Autoridad Nacional del Ambiente 1995a, 1995b).

The breeding biology of a few Amazona species has been studied in the wild; many of these studies occurred on Caribbean islands (Snyder et al. 1987, Gnam 1991, Rojas-Suárez 1994, Wilson et al. 1995) while others provide information on mainland species (EnkerlinHoeflich 1995, Enkerlin-Hoeflich and Hogan 1997, Renton and Salinas-Melgoza 1999, and Seixas and Mourão 2002). Additional data on breeding behavior come from studies of captive A. albifrons (Skeate 1984) and A. viridigenalis (Wozniak and Lanterman 1984). Overall, the studies have revealed that females typically spend long periods inside the nest during the incubation and early nestling periods, and depend, at least to some degree, on being fed by their mates. Four Amazona species in Mexico apparently select nest sites based on tree species, size, cavity height, and entrance size (Enkerlin-Hoeflich 1995, Renton and Salinas-Melgoza 1999).

Wright et al. (2001) summarized data from many field studies and showed that nest poaching is a principal cause of reproductive failure in Neotropical parrots, with poaching rates being higher at mainland sites than on 
islands, and lower in protected areas (e.g., nature reserves). While the impact of nest poaching on parrot reproductive success is clear, there are few studies that provide information on specific techniques used by poachers.

To date, there have been no published studies of the reproductive behavior of A. ochrocephala in Panama or other parts of its range. Here, we report our observations of the species' breeding behavior, describe the characteristics of nest sites and nest trees, and quantify reproductive success during two breeding seasons. We also present data regarding the poaching techniques used in the study area.

\section{METHODS}

Study area.-Fieldwork was conducted during the dry season (December-April) of 1997-1998 and 1998-1999 in the lowlands of Corregimiento de San Juan (San Lorenzo district) of the province of Chiriquí in western Panama. The natural vegetation in the area is tropical dry forest (following Holdridge's [1967] life zone classification) and mangrove, but in many places it has been cleared for agriculture and cattle grazing. Annual rainfall is $\sim 1,000 \mathrm{~mm}$; mean annual temperature is $\sim 30^{\circ} \mathrm{C}$, with mean temperatures of $35^{\circ}$ and $28^{\circ} \mathrm{C}$ during the dry and rainy seasons, respectively (Instituto de Recursos Hidráulicos y Electrificación 1998, 1999). The study area was located at $\sim 8^{\circ} 17^{\prime} 15^{\prime \prime} \mathrm{N}, 82^{\circ} 3^{\prime} 10^{\prime \prime} \mathrm{W}$ and encompassed an area of $\sim 8,800$ ha; $\sim 3,875$ ha had been partially cleared for agriculture and cattle grazing (on haciendas Miraflores, El Tekal, and Los Asentamientos de San Juan), and the remaining 4,925 ha were mangrove. The partially cleared areas still contained remnant patches of tropical dry forest dominated by Gliricidia sepium and Erythrina fusca trees, the lower-statured Curatella americana, and palms belonging to the genera Roystonea and Acrocomia (Acosta 1996).

Characterization of nest sites.-During the first breeding season (1997-1998), we only studied nests found in the mangrove habitat; in the following season (1998-1999), we extended our nest monitoring to include those found in the partially cleared dry forest habitat. We found 21 active nests during the 1 st year and 42 during the 2 nd year. Of the nests found in the 2 nd year, 14 had been used by parrots during the previous breeding season; therefore, to avoid pseudoreplication, our data on cavity and nest-tree characteristics represent 49 (and not 63) active nests. In the second breeding season, 20 of the nests were found in mangrove habitat, and the remaining 22 in the partially cleared dry forest.

To find nest cavities, we searched for trees with cavities, observed parrots flying and vocalizing in the area, and interviewed local residents and field laborers for information about nesting parrots. Nests were considered active if they contained A. o. panamensis eggs or nestlings.

To determine the availability of cavities, we searched for additional tree cavities near nest trees. By searching the area surrounding an occupied nest tree, we attempted to control for larger-scale habitat variation (e.g., vegetation density, canopy height, distance to feeding areas) that might have influenced cavity choice. All trees within $100 \mathrm{~m}$ of each nest tree were examined for the presence of large cavities (i.e., cavities similar in size to those occupied by parrots). For a given nest tree, two of the surrounding trees found to contain cavities were selected at random for inclusion in the sample of unoccupied cavities. If a selected tree contained more than one cavity, we selected one of them at random to provide data on cavity location and orientation. In the partially cleared dry forest habitat, we extended two of these searches beyond $100 \mathrm{~m}$ (108 and $116 \mathrm{~m}$ ) in order to find trees with large cavities. Determining that a cavity was similar in size to occupied cavities was admittedly subjective; therefore, we do not present any analyses comparing the dimensions of occupied versus unoccupied cavities.

We used leaf, flower, and/or fruit samples to identify the genus and species (where possible) of trees containing cavities. For each cavity we measured horizontal and vertical width of the cavity opening, inside vertical depth and cavity diameter (measured at the cavity floor), and distance from the ground to the lower edge of the cavity opening (see Saunders et al. 1982). Measurements were made using a $30-\mathrm{m}$ tape to a precision of 0.5 $\mathrm{cm}$, and were used to calculate the areas of the cavity entrance and cavity floor. For each cavity, we noted its location relative to the tree's structure-branch (cavity completely 
contained within a branch), trunk (cavity completely contained within the main trunk), and branch/trunk (cavity at the intersection of a branch and the trunk). We determined the orientation of the cavity opening using a compass, and measured each tree's height using a clinometer. We classified the physical condition of each tree-good, fair, poor, or deadusing the scheme outlined by Sauad et al. (1991; see also Saunders et al. 1982).

Behavioral observations.-We monitored 63 nests during the two breeding seasons: 21 during 1997-1998 and 42 during 1998-1999. Of the 63 nests, 5 were selected each year for detailed behavioral observations of parrots (hereafter referred to as focal nests). In the first field season, focal nests were chosen at random; during the second field season, nests were selected on the basis of their accessibility.

We made preliminary observations early in the breeding season (prior to egg-laying) at each of the focal nests. An observation period lasted $13 \mathrm{hr}$ (06:00 to 19:00 UTC-5). Each year, we watched three of the five focal nests for two preliminary observation periods, and the other two were watched for a single observation period. In most cases ( 9 of 16 observation periods), we conducted preliminary observations prior to capture of the focal individuals.

To identify the sex of focal individuals, we used nets (set up at dawn) to capture one or both members of each focal pair early in the field season (prior to the onset of breeding). We used nylon $(4.5 \times 15 \mathrm{~m})$ and cotton $(6 \times$ $8 \mathrm{~m}$ ) fishing nets (mist nets were not available) and suspended them using ropes and/or poles over the nest opening or across a flyway used by the birds. In both years, the sex of each captured individual was identified in the field by a veterinarian (R. De Obaldía) using a laparoscope. We then marked the female on the upper chest with Rhodamine B, so that she could be distinguished from the male in subsequent observations. Because the Rhodamine B marks faded after several weeks, the birds were subsequently marked passively by applying dye to the nest opening (see Eberhard 1998). This passive marking was done before the prior markings had faded completely, so that the identity of the newly marked birds was known. With this technique, the birds in- variably marked themselves on different parts of the body with unique patterns, so the male and female could be distinguished from one another.

For the remainder of each focal pair's breeding attempt, we made behavioral observations at $\sim 3$-day intervals. We observed during 3-hr periods when the parrots were most active (either 06:30-09:30 or 15:45-18:45), following the methodology used in other parrot studies (e.g., Eberhard 1998, Renton and Salinas-Melgoza 1999). The results reported here are based on $859 \mathrm{hr}$ of nest observation (208 hr were preliminary observations). We observed nests with the aid of binoculars from a distance of $\sim 15 \mathrm{~m}$ (the parrots quickly habituated to the observer's presence). During each observation period, we noted the following: time spent by the adults inside the nest; time spent in the nest area (defined as being in visual range of the observer, which was approximately $50-75 \mathrm{~m}$ in the mangrove habitat and approximately $100 \mathrm{~m}$ in the partially cleared dry forest areas); number of other parrots traveling with the focal individual when approaching or departing; and presence of other humans in the nesting area. Other general observations (allofeeding, allogrooming, vocal and plumage displays, appearances of nestlings at the cavity opening, age at which young left the nest) were noted $a d$ lib. When adults made short visits to the nest, presumably to feed young, we recorded total time in the nest cavity. Focal nest observations were made until 6 days after the last chick fledged, or 6 days after a nest was depredated or poached.

Three of the focal nests observed during the first breeding season (1997-1998) were in cavities that were re-occupied in the following breeding season, and were considered focal nests during the 2 nd year of the study. Because it is possible that pairs used the same cavity in consecutive years, our data might include some year-to-year pseudoreplication in the focal-nest behavioral observations. The adults were not permanently marked, so it was impossible to determine whether this occurred.

For the analysis of behavioral data, we divided the breeding season into four stages: pre-laying, laying, incubation, and nestling periods. The laying period began with the lay- 
ing of the first egg and extended until the last egg was laid; the incubation period began with the laying of the last egg and extended until the last egg hatched (in fact, incubation began when the first egg was laid, but for our data presentation and analyses, we defined the incubation period as described here to avoid overlap of data from the laying and incubation periods); the nestling period began with the hatching of the last egg and extended until the last nestling had fledged, or the nest was poached or depredated.

Nest checks.-During the laying and incubation periods, each focal and nonfocal nest was checked daily and its contents inspected; during the nestling period, we reduced the frequency of checks to once per week. On days when a focal nest was the object of behavioral observations, the nest was checked at the conclusion of the observation period, or at least $2 \mathrm{hr}$ before the start of an observation period. This was done to minimize disruption of the adults' behavior. At each nest check, we noted the presence of any new eggs (eggs were numbered with a pencil), used calipers to measure the dimensions (length and width) of new eggs, and noted laying and hatching dates. During the nestling period, we noted morphological characteristics of the hatchlings and the emergence and locations of new feathers, and recorded fledging dates. We also noted evidence of cavity enlargement by the parrots and presence of a nest lining. Although the frequency of nest checks was reduced during the nestling period, we visited nest trees 2 to 3 times per day in order to maintain a presence that, we hoped, would reduce the likelihood that our study nests would be poached.

Poaching interviews.-We obtained information on the techniques used by parrot poachers in the San Juan area through anonymous interviews of individuals actively engaged in the capture and sale of A. o. panamensis. Poachers were contacted with the help of an area resident who is familiar with the parrot trade around San Juan. A consistent set of questions or talking points was included in each interview, but the respondents were encouraged to offer any information that they might have regarding the parrots. The interview questions focused on the poaching of $A$. o. panamensis; however, additional informa- tion on other species was noted whenever mentioned by the respondents. All interviews were conducted by AMRC.

Statistical analyses.-Descriptive statistics (mean $\pm \mathrm{SD}$, range, percentage) are presented for nest site and behavioral data. Data from the 2 years are presented separately in tables, since the 2 nd year included data from nests in both partially cleared dry forest and mangrove habitats; however, the descriptive statistics presented in text summarize both years' data. We used the Lilliefors (Kolmogorov-Smirnov) test to check for normality prior to performing parametric tests. We performed chi-square tests of independence to test the hypothesis that parrots prefer cavities in certain tree species. For each habitat, we compared the number of nests (occupied cavities) in different tree species with the number of unoccupied cavities in those species. Chi-square tests of independence were also used to determine whether parrots showed a preference for trees in relatively good condition. We used circular statistics (Batschelet 1981) to analyze the orientation of nest-cavity openings, and performed Rayleigh tests to determine whether the orientations of occupied and unoccupied cavities were random. These tests were performed using R (R Development Core Team 2005); cavity openings facing upward were excluded from the orientation analyses. We performed a discriminant function analysis to determine whether there were significant differences between the dimensions of trees and cavities containing successful nests versus the dimensions of those with nests that were poached or depredated. Discriminant function analysis determines which variables (in our case, nest dimensions) discriminate between two or more groups (successful versus unsuccessful nests), and identifies those variables that contribute most to the differences between groups (Huberty 1994, Silva and Stam 1995). We employed a forward stepwise procedure to select among nine nest dimensions (see Table 1 ), with entry and removal $P$-values of 0.05 . We used linear regression to assess the degree to which time spent by the females in the nest changed through the nestling period. For analyses of data that were not normally distributed, we used Mann-Whitney $U$-tests and Wilcoxon tests. Statistical analyses (with the exception of circular statistics) 
TABLE 1. Dimensions of occupied cavities $(n=49)$ of Amazona ochrocephala panamensis in the lowlands of San Juan, Chiriquí, western Panama, 1997-1999.

\begin{tabular}{lcc}
\hline \multicolumn{1}{c}{ Measurement } & Mean $\pm \mathrm{SD}$ & Range \\
\hline Vertical depth $(\mathrm{cm})$ & $99.2 \pm 71.2$ & $34.8-445.0$ \\
Internal width $(\mathrm{cm})$ & $26.8 \pm 4.3$ & $18.1-34.0$ \\
Internal length $(\mathrm{cm})$ & $26.8 \pm 4.5$ & $16.5-36.0$ \\
Area of cavity floor $\left(\mathrm{cm}^{2}\right)$ & $575.9 \pm 175.1$ & $257.3-907.9$ \\
Area of cavity entrance $\left(\mathrm{cm}^{2}\right)$ & $229.7 \pm 63.0$ & $149.8-380.1$ \\
Horizontal diameter of cavity entrance $(\mathrm{cm})$ & $15.6 \pm 2.7$ & $10.9-19.8$ \\
Vertical diameter of cavity entrance $(\mathrm{cm})$ & $17.2 \pm 2.8$ & $12.0-22.5$ \\
Height of cavity entrance $(\mathrm{m})$ & $12.4 \pm 2.7$ & $9.2-16.5$ \\
Height of nest tree $(\mathrm{m})$ & $19.2 \pm 3.1$ & $10.7-26.1$ \\
\hline
\end{tabular}

were performed using Statistica 6.0 (StatSoft, Inc. 1998). For all tests, statistical significance was set at $\alpha=0.05$ and means are presented $\pm \mathrm{SD}$.

\section{RESULTS}

Characterization of nest sites.-In our study area, A. o. panamensis used a diversity of tree species for nesting. In mangrove habitat, active nest cavities were found in five tree species: Rhizophora mangle, $R$. brevistyla, Avicennia bicolor, Pelliciera rhizophorae, Mora oleifera. In partially cleared dry forest habitat, parrots were found nesting in two species of palms, Roystonea regia, Cocos nucifera, and in Ficus insipida trees. The most frequently used tree species were $R$. regia (18 of 49 nests) and $R$. mangle (13 of 49 nests). The tree species used least frequently were $A$. $b i$ color and $F$. insipida, each of which was used only once. Overall, parrots showed no preference for nesting cavities in any one tree species in either mangrove or dry forest habitat (mangrove: $\chi^{2}=0.813$, df $=4, P=0.94, n$ $=27$ nests; dry forest: $\chi^{2}=0.039, \mathrm{df}=2, P$ $=0.98, n=22$ nests). Rather, the use of tree species for nesting was proportional to cavity availability in those species. We found no evidence in either habitat type that any one tree species is more likely to develop cavities than the others (mangrove: $\chi^{2}=0.257, \mathrm{df}=4, P$ $=0.99, n=41$ cavities; dry forest: $\chi^{2}=$ 0.666 , df $=2, P=0.72, n=25$ cavities).

Characteristics of occupied and unoccupied cavities.-Breeding pairs preferred cavities that were relatively high above the ground and with dimensions similar to those reported for other Amazona species (see Table 1). The orientation of occupied cavity openings was non- random (Rayleigh test: $r=0.4408, P<0.001$, $n=39$ ), with a bias toward the northeast quadrant (25 of 39 occupied nests had orientations between $250^{\circ}$ and $360^{\circ}$ ). In contrast, the orientations of unoccupied cavities were randomly distributed (Rayleigh test; $r=$ 0.1495, $P=0.26, n=61$ ).

In both habitat types, we found that $A$. $o$. panamensis preferred trees with single cavities $\left(\chi^{2}=41.49, \mathrm{df}=2, P<0.001\right)$, possibly because trees with more than one cavity were in poorer condition than those with single cavities. Indeed, parrots preferred trees in relatively good condition. Forty-two of 49 (86\%) occupied trees were in good or fair condition, while 56 of $98(57 \%)$ unoccupied trees were in poor condition or they were dead $\left(\chi^{2}=\right.$ 24.5, df $=1, P<0.001)$. Comparing the location of cavities (branch, branch/trunk, or trunk) in occupied versus unoccupied trees indicated that the parrots had no preference for any particular cavity location $\left(\chi^{2}=0.807\right.$, df $=2, P=0.67$ ).

Pre-laying period.-We observed pairs of A. o. panamensis prospecting for nest sites early in each field season (13-30 December 1997, 21 December 1998-5 January 1999). Both members of the breeding pair participated in nest prospecting. On four occasions, we observed one of the two birds apparently take the lead in cautiously approaching and investigating the cavity while its partner remained perched in a nearby tree. Once a nest tree was selected, but before egg-laying began, the female (sex was known for focal pairs once they had been captured and marked) spent long periods of time within the nest cavity, while the male remained perched at the entrance or nearby. On two occasions in the mangrove 
habitat, a focal female was seen taking a twig into her nest cavity. In a third instance, an individual (sex unknown) took a leafy twig into its nest cavity in a $M$. oleifera tree. Inside 6 of the 49 monitored, occupied cavities, we found wood chips and leaves-materials that were a result of the parrots' chewing activities and/or brought in from outside the cavity.

Throughout the breeding season, pairs often perched together, grooming each other's neck, head, and wings. We observed no copulations or copulation attempts during our study. Prior to the onset of egg-laying, the male occasionally entered the nest cavity with the female and remained inside for several minutes (mean time inside $=3.40 \pm 0.44 \mathrm{~min}, n=$ 17). During these visits, it is likely that he was feeding the female, but it is also possible that copulations occurred. As the egg-laying period approached, the female increased the amount of time that she spent inside the nest cavity, emerging for a few minutes at intervals of $1.5-2.5 \mathrm{hr}$ to stretch her wings and legs before returning to the cavity. During this period, we observed eight instances in which the male presented his mate with flowers of Erythrina fusca or Gliricidia sepium, which the female subsequently consumed.

Egg-laying and incubation periods.-Egglaying in the monitored nests (focal and nonfocal) occurred from 15 December to 3 January (1997-1998) and 24 December to 13 January (1998-1999). Clutch size averaged $3.08 \pm 0.77$ eggs over both years of the study (Table 2), with no significant difference between years (Mann-Whitney $U$-test: $Z=$ $-0.584, P=0.56, n=63$ clutches). The mean laying interval was $2.16 \pm 0.92$ days (Table 2). Incubation began when the first egg was laid and was conducted exclusively by the female. The incubation period lasted $25.14 \pm$ 1.77 days.

During egg-laying and incubation, females spent most of their time inside the nest or perched nearby, and males were never seen entering the nest cavity, although they often remained perched nearby (Fig. 1). The amount of time the male spent with the female during the egg-laying period (the female's fertile period) versus during the incubation period did not differ (Wilcoxon test: $Z=1.48, P=0.14$, $n=10$ breeding attempts). During incubation, the female occasionally emerged from the nest

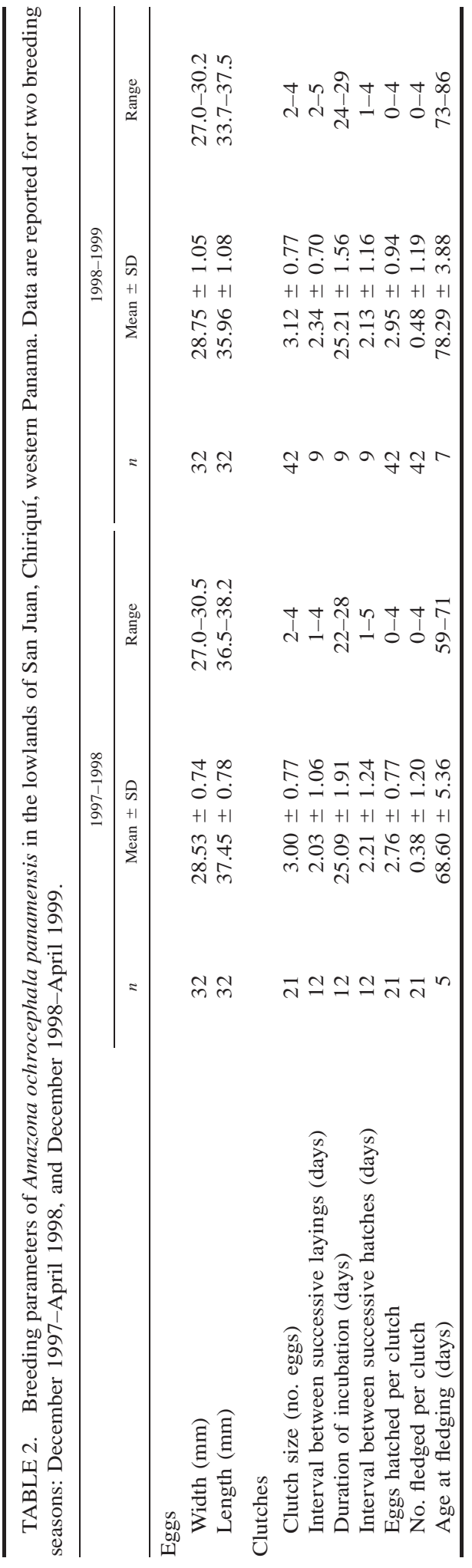


- Inside nest $\square$ Inside nest area $\square$ Outside nest area

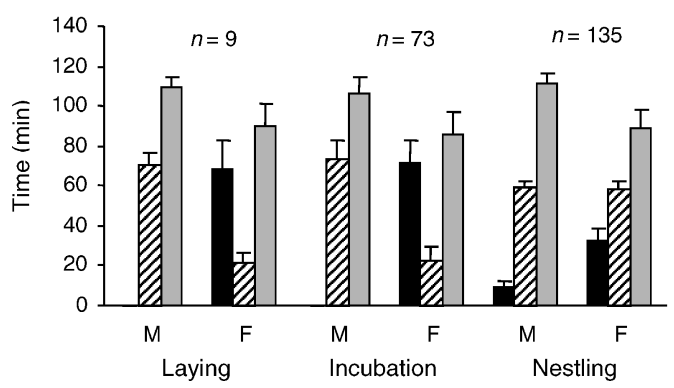

FIG. 1. Mean time (out of $180 \mathrm{~min}$ ) spent by adult Amazona ochrocephala panamensis parrots inside or near the nest, by nesting stage. Data are presented separately for males $(\mathrm{M})$ and females $(\mathrm{F})$; error bars correspond to standard deviations. Sample sizes refer to the number of $3-\mathrm{hr}$ observation periods. The number of pairs observed was as follows: 1997-1998, $n=5$ during laying, incubation, and nestling stages; 19981999, $n=5$ during laying and incubation stages, and $n=4$ during the nestling stage. Total observation times were 27, 219, and $405 \mathrm{hr}$ during the laying, incubation, and nestling stages, respectively.

for a short time $(8-17 \mathrm{~min})$ to perch at the cavity entrance or on a nearby branch, sometimes engaging in allogrooming with the male. On 10 occasions, the male was observed feeding the female near the nest. Males spent much of their time in the nest area, and typically departed on two foraging trips per dayone in the morning and the other in the late afternoon. Early in the morning and late in the afternoon, the female often left the nest areapossibly to forage with the male (Fig. 1) - and remained out of the nest area for $85.6 \pm 11.5$ $\min$ (range $=61-110 \mathrm{~min}$ ). For 27 of $83 \mathrm{de}$ partures, the pair departed with small groups of two to four other parrots-conspecifics and/or Amazona autumnalis. Upon their return, the pairs often flew in the company of other parrots (30 of 83 arrivals). At the end of the day, the male usually departed from the nest area $(65 \%$ of late afternoon observation periods in 1997-1998, and 76\% in 19981999), either alone or with other parrots as they passed by. On 11 occasions (involving 10 different nests), we made nocturnal nest checks during the incubation period and examined the nest area with a flashlight; on only three $(27 \%)$ of the checks did we see the male perched in the nest tree.

Nestling period.-Chicks hatched with their eyes closed, and their bodies were covered with a sparse white down that was later replaced by a gray down, as described by Forshaw (1989). Nestlings spent just over 2 months in their nests before fledging, varying somewhat between the 2 years of the study (mean age at fledging in 1997-1998 $=68.6$ \pm 5.36 days, $n=5$ fledglings; mean age at fledging in 1998-1999 $=78.3 \pm 3.88$ days, $n$ $=7$ fledglings). Young fledged between 22 March and 5 April in 1998, and between 6 and 24 April in 1999; those hatched during the 1st year fledged in less time than did those hatched during the 2nd year (Mann-Whitney $U$-test: $Z=-2.94, n=12$ fledglings, $P=$ 0.003).

We made six nocturnal visits to nests and on five of the visits ( $83 \%$ ) the male was found in the nest area, but never inside the nest cavity; in three cases, he was perched near the nest entrance, and twice he was perched a few meters away in a nearby tree. On all six visits, the female was inside the nest (on four of these occasions, the female briefly came to the nest entrance to look out and then quietly went back inside; on the other two visits, she exited the nest and returned $\sim 30$ min later).

During the nestling period, we typically found the female inside the nest as we began each observation period (114 of 135 observation periods). She would spend much of her time brooding recently hatched young, but as the nestling period progressed, she decreased the amount of time spent in the nest (linear regression: $F_{1,132}=419.08, P<0.001, R^{2}=$ $0.76, b=-2.44)$. When outside of the nest, she perched nearby and engaged in allogrooming with her mate and/or she left the nest area, presumably to forage (Fig. 1). Each day during this period, both the male and female would follow their foraging trips with two to four short visits to the nest cavity, presumably to feed the nestlings (males: mean duration $=5.5 \pm 1.3 \mathrm{~min}$, range $=2.2-8.3$, $n=135$ observation periods; females: mean duration $=5.1 \pm 1.2 \mathrm{~min}$, range $=2.4-7.5$, $n=135$ observation periods).

Nestlings acquired their plumage rather slowly. The flight feathers were the first to appear, with pin feathers for the remiges beginning to emerge when nestlings were 16 to 28 days old. Green contour pin feathers on the wings and yellow contour feathers on the head 
began to unsheath at 26-30 days, and contour feathers on the legs and back began to unsheath at 35-38 days. At $\sim 40-42$ days, the green feathers on the head and red feathers at the bend of the wing began to unsheath. Finally, at $\sim 49-52$ days, the tail feathers were completely unsheathed. About 2 weeks before leaving the nest, the nestlings began to perch at the cavity opening. Fledging was asynchronous, and the age at which young left the nest ranged from 59 to 86 days (see Table 2). We observed the nestlings' first flight from the nest on seven occasions; five flights occurred in the morning and two in the late afternoon. The first flights were relatively short (mean distance $=34.6 \pm 8.0 \mathrm{~m}$, range $=25.0-48.5$, $n=7$ fledglings), low, and quiet, and the young were accompanied by one or both adults. After the last chick in a clutch had fledged, neither the young nor the adults entered the nest cavity again; for at least 6 more days, however, the adults continued to visit the nest area. Breeding pairs whose nests were poached by humans or failed due to natural predation did not make a second breeding attempt in the same cavity that year; however, they continued to visit the nest area for at least 6 days following nest failure.

Breeding success.-We obtained productivity data for 63 breeding attempts (Table 2). Overall, breeding success of $A$. $O$. panamensis was very low. Over both breeding seasons, only $12.7 \%$ (8 of 63 ) of nests fledged young. Of the remaining nests, $9.5 \%$ (6 of 63) failed due to natural predation at the nestling stage, all of which we visually confirmed as predation by boas (Boa constrictor). The principal cause of breeding failure was nest poaching by humans. A total of $77.8 \%$ of nests (49 of 63) were poached or presumed to have been poached. Poachers accessed nest contents by chopping holes in trunks at the level of the nest cavity (17 of 49 poached nests), climbing trees to reach nests (27 of 49), and less frequently by felling trees ( 5 of 49 ). The disappearance of nestlings often coincided with evidence of machete cutting of understory vegetation near the nest tree (17 of 49 poached nests).

Fourteen of the 19 cavities $(74 \%)$ containing nests that failed due to predation or poaching during the 1 st year were reused during the following breeding season. Only 8 of 49 cav- ities monitored during one or both breeding seasons housed nests that successfully fledged young, but we found no evidence of a relationship between breeding success and the dimensions of nest trees or nest cavities. Discriminant function analysis indicated that the dimensions of trees and cavities containing successful versus failed (poached or depredated) nests did not differ (Wilks' Lambda = $0.7468, F_{9,39}=1.47, P=0.19, n=49$ nests); only cavity depth contributed significantly to the discriminant function (Wilks' Lambda $=$ 0.8953, $P=0.008$ ).

Poaching techniques and illegal trade.Eighteen parrot poachers were interviewed, and they described a range of poaching strategies that included the removal of unhatched eggs, newly hatched nestlings, fully feathered nestlings, and the capture of recently fledged juveniles. The majority of poachers (13 of 18) preferred fully feathered nestlings $\sim 40$ days old and only one of the poachers took newly hatched young ( 3 to 8 days old). Relatively few poachers ( 2 of 18) took eggs from the nest, and the remainder ( 2 of 18 ) preferred to capture juveniles that had already fledged. None of the poachers targeted adult parrots.

More than three quarters of the poachers (14 of 18) considered the demand for $A$. $O$. panamensis nestlings to be very high, and said that they always had customers lined up to purchase birds even before they had been taken from their nests. Many of the poached birds are sold locally to customers in Chiriquí, but poachers indicated that vacationers from Panama City and truck drivers involved in the transport of merchandise between Panama and Costa Rica pay the highest prices (as much as US $\$ 100$ for a fully feathered and healthy parrot chick). Half of the poachers said that they typically sold parrot nestlings for $\$ 40$ or more; most of the others ( 8 of $18,44.4 \%$ ) sold nestlings for \$30-39, and only one of the poachers sold nestlings for \$20-29. Poachers were not asked to reveal total annual earnings from poaching, but five volunteered this information: four indicated that they typically made \$200-350 per year and one said that he never earned less than $\$ 200$ annually and sometimes made as much as $\$ 750$ per year. For comparison, the typical monthly salary for a farm laborer in the area is $\$ 130$. According to a 1990 census (Dirección General de Estadística y 
Censo de Panamá 1991), the human population in the study area was approximately 2,358 , but the number of people involved in poaching activities is difficult to estimate. Poaching of parrot nestlings is punishable by fines of up to $\$ 1,000$, but poachers indicated that if they were caught, the authorities typically seized the nestlings and did not impose any further punishment.

Fifteen of the poachers interviewed (83\%) said that they usually collected 6-9 nestlings per breeding season, and the remaining individuals typically collected 2-5 nestlings per season. Most of the poachers (13 of 18) said that they have been collecting and selling parrot nestlings for 7-13 years, and the others have done so for 1-6 years. Eleven poachers $(61 \%)$ noted that, in the past, they had also taken A. autumnalis nestlings, but no longer did so because this species is not a good imitator of human speech and therefore is much less marketable than $A$. o. panamensis. Eight poachers said that both of these species were hunted for food in eastern Chiriquí, but five of the men indicated that this practice is no longer common, especially in the case of $A$. $o$. panamensis, which could be sold for a relatively high price. Recently, some poachers have begun to use yellow dye on the forehead feathers of A. autumnalis and even Aratinga pertinax (both of which are less desirable than A. ochrocephala in the pet trade), in order to sell them to unsuspecting buyers as $A$. ochrocephala (AMRC pers. obs.). These data indicate that poaching of $A$. $o$. panamensis is not a new phenomenon and has likely impacted resident populations of the species by reducing recruitment of juveniles.

\section{DISCUSSION}

Characterization of nesting habitats and cavities used for breeding.-Breeding pairs of A. o. panamensis preferred relatively large cavities high up in trees and palms. The dimensions of the cavities used by these parrots was within the range of those reported for other Amazona species, such as A. vittata (Snyder et al. 1987), A. leucocephala bahamensis (Gnam 1991) and A. barbadensis (Rojas-Suárez 1994).

We found no evidence that $A$. o. panamensis prefers to nest in any one species of tree; the frequency of nests in different tree species reflected the frequency of cavity occurrence in those species. Saunders (1979) found a similar lack of preference in a study of Calyptorhynchus baudinii latirostris; in three of four nesting areas studied, the dominant tree species housed the majority of nests. Snyder et al. (1987) found that most A. vittata nests are in palo colorado (Cyrilla racemiflora), but this was due to the scarcity of cavities in other tree species found in the parrots' habitat. In our study, breeding pairs preferred trees in good or fair condition. This contrasts with the finding of Sauad et al. (1991), who found that $72 \%$ of A. aestiva nests were in trees that were in poor condition or dead. Similarly, Calyptorhynchus magnificus tended to nest in dead trees more often than expected by chance (Saunders et al. 1982).

In our study area in western Panama, we found that openings of cavities occupied by breeding A. o. panamensis tended to be oriented toward the northeast. A similar preference for certain orientations has been documented for several other parrots (RodríguezVidal 1959, Saunders 1979; but see Saunders et al. 1982, Sauad et al. 1991).

Breeding behavior.-The breeding behavior of A. o. panamensis is similar to that reported for other psittacids. Pairs are socially monogamous and both members of the pair contribute significantly to nest defense and caring of young. Allofeeding of the female by her mate, which we observed on several occasions, is typical of breeding parrots (Skeate 1984, Snyder et al. 1987, Gnam 1991, Eberhard 1998), especially early in the breeding cycle (Snyder et al. 1987, Eberhard 1998). Nevertheless, female A. o. panamensis did not appear to depend on their mates for food; they regularly left the nest area with their mates, presumably to forage.

Females typically laid eggs at 2-day intervals, as reported for other congeners (A. vittata, Snyder et al. 1987; A. leucocephala bahamensis, Gnam 1991; and A. barbadensis, Rojas-Suárez 1994), though they occasionally laid eggs on successive days or at intervals of up to 5 days. Clutch size varied from two to four eggs, as reported for A. vittata (Snyder et al. 1987), and the duration of incubation was similar to that reported for other Amazona parrots (Low 1972, Skeate 1984, Snyder et al. 1987, and Rojas-Suárez 1994). As in many 
other parrots (Forshaw 1989), incubation began when the first egg was laid, resulting in asynchronous hatching, and the female was responsible for incubation. During incubation, the female occasionally emerged from the nest for a few minutes at a time to stretch, groom, and participate in nest defense; in the early morning and late afternoon she often departed for longer times, possibly to forage. The substantial proportion of time spent outside of the nest during this period was greater than that reported for other Amazona parrots (e.g., Snyder et al. 1987, Wilson et al. 1995, Renton and Salinas-Melgoza 1999). In A. vittata, low nest attendance and long recesses by female parrots were associated with failed nesting attempts (Wilson et al. 1997); we observed similar behaviors in A. o. panamensis, but they did not appear to negatively impact breeding success, and the duration of incubation and the number of eggs hatched per clutch in our study were similar to those reported for other Amazona parrots (Low 1972, Snyder et al. 1987, Gnam 1991, Rojas-Suárez 1994). The long departures by A. o. panamensis females might be due to habitat fragmentation in our study area, which in turn has disrupted the parrots' foraging patterns, as observed by Saunders (1990) in a study of Carnaby's Cockatoo (Calyptorhynchus funereus latirostris) in agricultural areas.

During incubation, we never saw the male enter the nest; this contrasts with observations of $A$. albifrons (Skeate 1984) and A. vittata (Snyder et al. 1987), in which males occasionally enter the nest during this period. In A. o. panamensis, the male spent much of his time near the nest while his mate was incubating, possibly to alert her to approaching predators or prevent extra-pair copulations by his mate with other males; however, the time the male spent in the nest area did not differ between the egg-laying (when the female is fertile) and incubation periods, suggesting that he was not mate-guarding.

The female was apparently responsible for feeding the newly hatched chicks, but a few days after the eggs had hatched, the male began to enter the nest regularly, presumably to feed the young. This also has been reported for other Amazona parrots, including A. albifrons (Skeate 1984), A. l. bahamensis (Gnam 1991), and A. vittata (Snyder et al. 1987, Wil- son et al. 1995). As the nestlings grew, the female gradually reduced the amount of time she spent in the nest with them. She ceased brooding the young during the day when the oldest nestling was 18 to 25 days old, similar to that observed in other Amazona species (e.g., Snyder et al. 1987, Enkerlin-Hoeflich and Hogan 1997, Renton and Salinas-Melgoza 1999).

Chicks of a single clutch usually fledged on different days, as reported for A. vittata (Snyder et al. 1987) and A. l. bahamensis (Gnam 1991). Mean age at fledging was greater than that reported by Snyder et al. (1987) for $A$. vittata, by Rojas-Suárez (1994) for A. barbadensis, and by Renton and Salinas-Melgoza (1999) for A. finschi. As described for A. $l$. bahamensis (Gnam 1991), fledglings were accompanied by one or both parents on their first flight, but the flights of $A$. o. panamensis fledglings were shorter. After leaving the nest, A. o. panamensis fledglings were very quiet, probably to avoid attracting the attention of predators; similar cryptic behavior has been observed in A. vittata (Snyder et al. 1987).

Breeding success.-In our study area, the breeding success of $A$. $o$. panamensis was low, principally due to poaching, and to a lesser extent to natural predation by boas. Habitat loss due to deforestation, which often involves felling of the largest trees, has been cited as an important cause of population declines among parrots (Juniper and Parr 1998). However, in the case of $A$. o. panamensis in western Panama, our results indicate that breeding is not limited by the availability of nesting sites, even though much of the area has been partially cleared. The very low rate of breeding success is instead due to extremely high poaching rates fueled by demands of the local pet trade. Low salaries and the lack of employment opportunities in the San Juan area undoubtedly drive individuals to poach parrot nestlings. Although the activity is illegal and punishable by fines of up to $\$ 1,000$, antipoaching laws are only weakly enforced. Because favored poaching techniques are focused on collecting nestlings, recruitment into the A. o. panamensis population is severely reduced, and the population is in danger of a rapid and precipitous decline as the adults age and are not replaced by individuals from younger age classes. 


\section{ACKNOWLEDGMENTS}

We thank the owners and laborers of Hacienda El Tekal, Hacienda Miraflores, and Hacienda Los Asentamientos de San Juan for their collaboration and for allowing access to their properties. Partial financial support was provided by the German Technical Cooperation Agency through its Proyecto Agroforestal Ngöbe-ANAM-GTZ. We are grateful that some of the parrot poachers were willing to reveal information about their activities, which may help in developing future conservation measures. We also thank the residents of the Corregimiento de San Juan, especially those engaged in the collection and sale of parrots in the local pet trade, for sharing information on their poaching activities. Two poachers were helpful in locating nests as well as establishing contacts with poachers and others involved in the local parrot trade. We thank K. Harms for assistance with performing statistical tests in R, and F. Gómez and E. de Morris for their comments on an early version of the manuscript; the manuscript also benefited from extensive comments provided by three anonymous reviewers.

\section{LITERATURE CITED}

Acosta, J. L. 1996. Inventario florístico en dos comunidades del Distrito de San Lorenzo, Chiriquí. Tesis de Licenciatura, Escuela de Biología, Universidad de Panamá, Ciudad de Panamá, Panamá.

Asociación Nacional Para la Conservación de La NAturalezA. 1995. Fauna silvestre en peligro de extinción. Grupo Editorial del Istmo, Ciudad de Panamá, Panamá.

Autoridad Nacional del Ambiente. 1995a. Especies animales en peligro de extinción en Panamá. Grupo Editorial del Istmo, Ciudad de Panamá, Panamá.

Autoridad NaCiOnAl del AmbIEnTE. 1995b. Informes de los operativos de decomiso de aves en peligro de extinción en Panamá. Dirección Regional de la Provincia de Chiriquí, David, Chiriquí, Panamá.

Batschelet, E. 1981. Circular statistics in biology. Academic Press, New York.

Dirección General de Estadística y Censo. 1991. Censos nacionales de población y vivienda, 13 de mayo de 1990. Resultados finales básicos: total del país. Contraloría General de la República, Ciudad de Panamá, Panamá.

EBERHARD, J. R. 1998. Breeding biology of the Monk Parakeet. Wilson Bulletin 110:463-473.

Eberhard, J. R. And E. Bermingham. 2004. Phylogeny and biogeography of the Amazona ochrocephala complex. Auk 121:318-332.

ENKERLIN-Hoeflich, E. C. 1995. Comparative ecology and reproductive biology of three species of Amazona parrots in northeastern Mexico. Ph.D. dissertation, Texas A\&M University, College Station.

Enkerlin-Hoeflich, E. C. And K. M. Hogan. 1997. Red-crowned Parrot (Amazona viridigenalis). The Birds of North America, no. 292.

Forshaw, J. M. 1989. Parrots of the world, 3rd (re- vised) ed. Lansdowne Editions, Melbourne, Australia.

GNAM, R. S. 1991. Nesting behaviour of the Bahama Parrot (Amazona leucocephala bahamensis) on Abaco Island, Bahamas. Acta Congressus Internationalis Ornithologici 20:673-680.

Holdridge, L. R. 1967. Life zone ecology. Tropical Science Center, San Jose, Costa Rica.

HuberTy, C. J. 1994. Applied discriminant analysis. John Wiley and Sons, Athens, Georgia.

INSTITUTO DE RECURSOS HidRÁUlicos Y ElECTRIFICACIÓN. 1998. Informe anual de temperatura y precipitación pluvial en la provincia de Chiriquí. Departamento de Hidrometeorología-Sección Chiriquí, David, Panamá.

InSTITUTO DE RECURSOS HidRÁUlicos y EleCtrificACIÓN. 1999. Informe técnico: evaluación anual de precipitación pluvial, temperatura y húmedad relativa de las zonas bajas de la provincia de Chiriquí. Departamento de Hidrometeorología-Sección Chiriquí, David, Panamá.

Juniper, T. AND M. PARR. 1998. Parrots: a guide to the parrots of the world. Yale University Press, New Haven, Connecticut.

Low, R. 1972. The parrots of South America. John Gifford, London, United Kingdom.

R Development Core Team. 2005. R: a language and environment for statistical computing. R Foundation for Statistical Computing, Vienna, Austria.

Renton, K. And A. SAlinas-Melgoza. 1999. Nesting behavior of the Lilac-crowned Parrot. Wilson Bulletin 111:488-493.

Ridgely, R. S. 1981. The current distribution and status of mainland Neotropical parrots. Pages 233384 in Conservation of New World parrots (R. F. Pasquier, Ed.). International Council for Bird Preservation Technical Bulletin, no. 1. Smithsonian Press, Washington, D.C.

Rodríguez-Vidal, J. A. 1959. Puerto Rican parrot study. Monographs of the Department of Agriculture and Commerce, Puerto Rico, no. 1.

RojAs-SuÁREZ, F. 1994. Biología reproductiva de la Cotorra Amazona barbadensis (Aves: Psittaciformes) en la Península de Macanao, Estado de Nueva Esparta. Pages 73-87 in Biología y conservación de los psitácidos de Venezuela (G. Morales, I. Novo, D. Bigio, A. Luy, and F. Rojas-Suárez, Eds.). Editorial Giavimar, Caracas, Venezuela.

SAuad, J. J., V. Nuñez, J. L. Garrido, S. Mosa, M. E. CÁlzon, And Z. M. Chorolque. 1991. Ambientes de nidificación del Loro Hablador Amazona aestiva. Salta, Argentina. III. Características de los árboles nido. Publicación Técnica, no. 5, Manejo de Fauna. Universidad Nacional de Salta, Salta, Argentina.

SAUNDERS, D. A. 1979. The availability of tree hollows for use as nests sites by White-tailed Black Cockatoos. Australian Wildlife Research 6:205-216.

SAunders, D. A. 1990. Problems of survival in an extensively cultivated landscape: the case of Car- 
naby's Cockatoo (Calyptorhynchus funereus latirostris). Biological Conservation 54:277-290.

SAunders, D. A., G. T. SMith, AND I. Rowley. 1982.

The availability and dimensions of tree hollows that provide nest sites for cockatoos (Psittaciformes) in Western Australia. Australian Wildlife Research 9:541-556.

SeIXAs, G. H. F. AND G. M. Mourão. 2002. Nesting success and hatching survival of the Blue-fronted Amazon (Amazona aestiva) in the Pantanal of Mato Grosso do Sul, Brazil. Journal of Field Ornithology 73:399-409.

Silva, A. P. D. AND A. Stam. 1995. Discriminant analysis. Pages 277-318 in Reading and understanding multivariate statistics (L. G. Grimm and P. R. Yarnold, Eds.). American Psychological Association, Washington, D.C.

SkeAte, S. T. 1984. Courtship and reproductive behaviour of captive White-fronted Amazon Parrots (Amazona albifrons). Bird Behaviour 5:103-109.

SNyder, N. F. R., J. W. Wiley, AND C. B. Kepler.
1987. The parrots of Luquillo: natural history and conservation of the Puerto Rican Parrot. Western Foundation of Vertebrate Zoology, Los Angeles, California.

StatSoft, InC. 1998. Statistica 6.0. Statsoft, Inc., Tulsa, Oklahoma.

Wilson, K. A., R. Field, AND M. H. WILsON. 1995. Successful nesting behavior of Puerto Rican Parrots. Wilson Bulletin 107:518-529.

Wilson, K. A., M. H. Wilson, AND R. Field. 1997. Behavior of Puerto Rican Parrots during failed nesting attempts. Wilson Bulletin 109:490-503.

WozNiAK, S. AND W. LANTERMAN. 1984. Breeding the Green-cheeked Amazon Parrot Amazona viridigenalis at the Ornithological Institute, Oberhausen, Germany. Avicultural Magazine 90:195-197.

Wright, T. F., C. A. Toft, E. ENKerlin-Hoeflich, J. Gonzalez-Elizondo, M. Albornoz, A. RoDRíGUEZ-FERRARO, F. RoJAS-SUÁREZ, ET AL. 2001. Nest poaching in Neotropical parrots. Conservation Biology 15:710-720. 